Reporte de caso

\title{
Histiocitosis de Células de Langerhans
}

\author{
Renata Da Fonseca ${ }^{1}$; \\ Lydia López Del-Valle ${ }^{2}$; \\ Lis Arocho ${ }^{3}$; \\ Diego González ${ }^{4}$; \\ José González ;
}

Edgar Perales de Anda ${ }^{6}$;

Damaris Molina-Negrón ${ }^{7}$

\section{Resumen}

Histiocitosis de células de Langerhans (HCL) es una singular enfermedad idiopática, la cual se caracteriza por proliferación clónica de células de Langerhans. HCL puede presentarse como una simple lesión osteolitica o puede afectar múltiples sistemas en el cuerpo. Oralmente se puede preceder manifestaciones sistémicas o simular desordenes infecciosos/inflamatorios. El reporte de este caso presenta a un varón de 3 años de edad referido a la clínica del programa Postdoctoral de Odontopediatria en la Universidad de Puerto Rico para evaluar una posible enfermedad periodontal en los segundos mola- res deciduos. En la evaluación clínica se observó inflamación extraoral bilateral en los lados izquierdo y derecho del rostro obliterando los ángulos mandibulares. La piel suprayacente estaba intacta y sin sintomatología. En la evaluación intraoral mostró inflamación localizada en la mucosa suprayacente de los molares deciduos en ambos lados con cierto grado de movilidad. Este caso ejemplifica la necesidad tanto de pediatras como odontopediatras de estar conscientes que HCL puede simular lesiones periodontales.

Palabras Clave: Infante; Histiocitosis de células de Langerhans; periodontitis; manifestaciones orales.

Relato de caso

\section{Histiocitose de Células de Langerhans}

\section{Resumo}

Histiocitose de Células de Langerhans (HCL) é uma enfermidade idiopática singular, a qual ca- racteriza-se pela proliferação crônica das células de Langerhans. A HCL pode se apresentar de duas formas distintas; como uma única lesão osteolítica ou, afetar múltiplos sistemas do corpo humano.

\footnotetext{
${ }^{1}$ Residente Programa Postdoctoral de Odontopediatria, Universidad de Puerto Rico, Escuela de Medicina Dental, San Juan, P.R.

${ }^{2}$ Profesor, Universidad de Puerto Rico, Escuela de Medicina Dental, San Juan, P.R.

${ }^{3}$ Profesor Auxiliar, Programa Graduado de Cirugía Oral y Maxilofacial, Universidad de Puerto Rico, Escuela de Medicina Dental, San Juan, P.R.

${ }^{4}$ Residente Programa Graduado de Cirugía Oral y Maxilofacial, Universidad de Puerto Rico, Escuela de Medicina Dental, San Juan, P.R.

${ }^{5}$ Profesor Jefe de Sección Endodoncia y Periodoncia Universidad de Puerto Rico, Escuela de Medicina Dental, San Juan, P.R.

${ }^{6}$ Residente Programa Postdoctoral de Odontopediatria, Universidad de Puerto Rico, Escuela de Medicina Dental, San Juan, P.R.

${ }^{7}$ Profesor, Programa Postdoctoral de Odontopediatria, Universidad de Puerto Rico, Escuela de Medicina Dental, San Juan, P.R.
} 
Na região bucal podem ocorrer manifestações sistêmicas que simulem desordens de origem infecciosas/ inflamatórias. O relato deste caso trata-se de um menino de 3 anos de idade, recomendado à Clinica do Programa Pós-Doutorado de Odontopediatria da Universidade de Puerto Rico, para avaliar a possível doença periodontal nos segundos molares decíduos. $\mathrm{Na}$ avaliação clínica observou-se inflamação extraoral bilateral nos lados esquerdo e direito do rosto obstruindo os ângulos mandibulares. O tecido facial adjacente encontrava-se intacto e sem sintomatologia.
A avaliação intraoral, no entanto, constatou inflamação localizada na mucosa vestibular e certo grau de mobilidade nos molares decíduos em ambos os lados. Este caso demonstra a importância de se ampliar a divulgação da $\mathrm{LCH}$, como também o fato que a mesma pode simular lesões periodontais, principalmente entre pediatras e odontopediatras, com o intuito de aperfeiçoar o manejo clínico das crianças portadoras da doença.

Palavras-chaves: Criança, Histiocitose de células de Langerhans; periodontitis, manifestações orais

Critical Review Article

\section{Langerhans Cell Histiocytosis}

\begin{abstract}
Langerhans cell histiocytosis ( $\mathrm{LCH})$ is a rare idiopathic disease characterized by the clonal proliferation of Langerhans cells. LCH may appear as a single osteolytic lesion or can affect many body systems. Oral involvement may predate systemic manifestations or mimic infectious/inflammatory disorders. This case report involves a 3-year-old boy referred to the pediatric dentistry residency clinic at the University of Puerto Rico to evaluate possible periodontal disease on primary second lower molars. Examination revealed bilateral extra-oral swelling on the left and right side of the face obliterating the mandibular angles. The overlying skin was intact and symptomless. An intraoral examination showed localized swelling of the overlying mucosa from the lower primary right and left molars with some degree
\end{abstract}

of mobility on both the right and left second primary molars. This case illustrates the need for pediatricians and pediatric dentists to be aware of LCH mimicking periodontal lesions.

Keywords: infants; Langerhans cell histiocytosis; periodontitis; oral manifestations

\section{Introducción}

Histiocitosis de células de Langerhans es una singular enfermedad idiopática que se caracteriza por la proliferación clónica de células dendríticas de Langerhans con un carácter agresivo. Hasta la fecha la existe controversia si es un proceso maligno o una condición inflamatoria mediada por inmunidad ${ }^{1}$. Esta enfermedad diversa consta de tres lesiones morfológicamente similares; Granuloma Eosinofilico, Enfermedad 
de Hand-Christian-Schuller y Enfermedad de Letterer-Siwe ${ }^{2}$, tienen en común una liberación anormal de células histoliticas con gránulos Birbeck característicos.

Bajo condiciones normales, las células de Langerhans ayudan a regular el sistema inmunológico auxiliando al cuerpo a combatir infecciones. Exceso de células de Langerhans inmaduras exhiben una diversidad clínica extrema y cursos impredecibles ${ }^{3}$ que usualmente causan destrucción y deterioro de ciertos órganos, el desarrollo de tumores nombrados granulomas que provocan inflamación y dolor de las áreas afectadas entre otros síntomas. De acuerdo con el Writing Group of the Hystiocite Society; HCL tiene predilección por hombres sobre mujeres en un radio de 2:1.

Predominantemente afecta a 1 por cada 200,000 niños por año, con una incidencia máxima entre 1 y 3 años de edad, pero se puede desarrollar a cualquier edad ${ }^{4}$. Existente múltiples factores clave en manifestaciones clínicas que incluye la localización de las lesiones, número de áreas involucradas el alcance de que órganos están comprometidos. Implicaciones óseas y lesiones en tejidos blandos orales son las de mayor prevalencia y radiográficamente muestra lesiones osteoliticas o puede afectar múltiples sistemas, comúnmente en cabeza y cuello. Oralmente se pueden preceder manifestaciones sistémicas o simular desordenes infecciosos/inflamatorios. El propósito de este documento es reportar un caso que involucra HCL afectando la mandíbula de un varón de 3 años de edad; a quien la lesión fue tratada interviniendo con un curetaje quirúrgico y con extracciones de los dientes afectados, a su vez tratamiento un de quimioterapia que lleva en proceso por un año.

\section{REPORTE DE CASO}

Paciente varón de 3 años de edad fue referido a la clínica del Programa Postdoctoral de Odontopediatria en la Universidad de Puerto Rico, Escuela de Medicina Dental. El paciente fue referido por un dentista de práctica privada para evaluación de una posible enfermedad periodontal en los segundos molares deciduos.

El representante otorgó consentimiento y informado para la publicación de la información y fotografías referentes al caso.

El único hallazgo significativo en el historial médico del paciente es asma. El paciente no reporta signos de dolor o malestar, buen régimen de alimentación y descanso. En el examen extra oral se observa inflamación bilateral del rostro obliterando ambos ángulos mandibulares. La piel del rostro del paciente está intacta y síntomas.

Durante el examen intraoral, en el arco mandibular se observa inflamación localizada y de apariencia hemorrágica en el tejido gingival de la superficie bucal de los molares mandibulares deciduos con cierto grado de movilidad. El resto de los tejidos se observaron dentro de los límites normales. La impresión inicial era una variación de periodontitis localizada acompañada de acumulación generalizada de placa en la mayoría de los dientes del paciente. (Fig. 1).

La radiografía panorámica reveló pérdida ósea bilateral en los segundos molares mandibulares deciduos con compromiso de los gérmenes del primer molar mandibular permanente. Aparentemente el germen del segundo premolar mandibular izquierdo está ausente. Una lesión radiolucida multilocular con márgenes irregulares se aprecia del lado izquierdo (Fig. 2C). La cefalometría late 

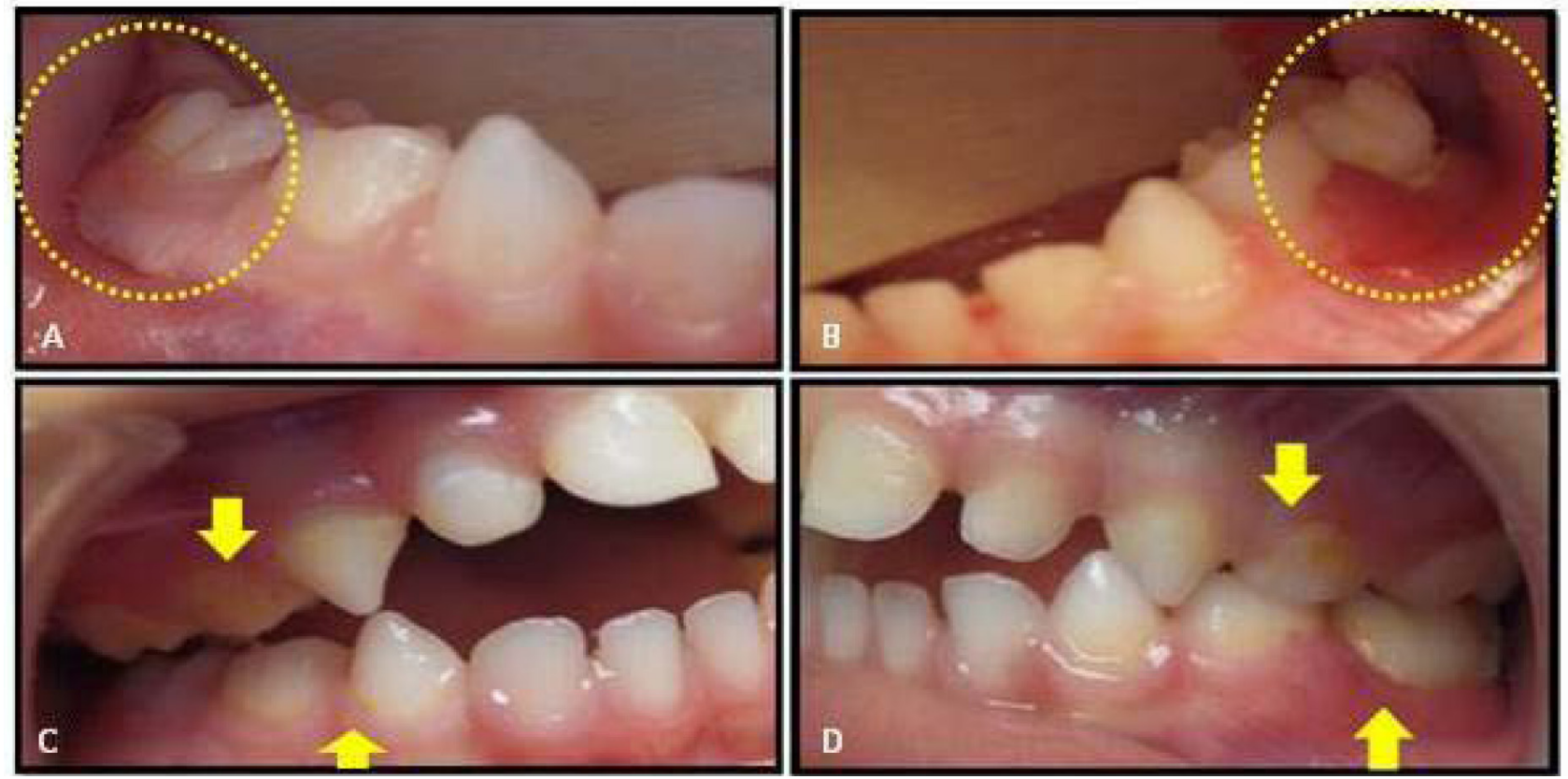

Figura 1.

ral de cráneo demuestra hipodensidad del lóbulo parietal (Fig. 2C). Una tomografía computarizada (CT) reveló dos lesiones líticas en ambos lados de la región premolar del cuerpo de la mandíbula con dientes flotando dentro. La lesión del lado izquierdo mide aproximadamente $2.5 \times 1.7 \mathrm{~cm}$ y la lesión del lado derecho mide $2.0 \times 1.4 \mathrm{~cm}$ con márgenes corticales irregulares y áreas sin márgenes corticales. La tomografía computarizada (CT) también identifico nódulos cervicales superiores agrandados, algunos en el lado derecho en el área retromandibular midiendo $1.3 \times 1.0 \mathrm{~cm}$, lateral a la vaina de la carótida $2.2 \times 1.5 \mathrm{~cm}$, área retromandibular izquierda $1.1 \times 1.0 \mathrm{~cm}$, lateral a la vaina de la carótida izquierda $1.9 \times 1.3 \mathrm{~cm}$. (Fig. 2B).

En el conteo sanguíneo completo reveló un incremento en el conteo plaquetario y en el panel metabólico altos niveles de fosfatasa alcalina, aspartato y aminotransferasa.

Después de una evaluación clínica del paciente por un periodoncista y cirujano oral se tomó la decisión de llevar al paciente a sala de operaciones para efectuar una biopsia excisional de ambas lesiones, extracción de los segundos molares mandibulares deciduos y primer molar mandibular permanente bajo anestesia general. Durante el procedimiento el germen del segundo premolar mandibular permanente estaba comprometido por la lesión y fue removido. El curetaje fue extenso y no fue terminado hasta observar tejido óseo sano y haber removido todo el tejido irregular. Los especímenes fueron identificados y enviado para evaluación a patología. El reporte patológico confirmó que ambas lesiones mandibulares eran consistentes con el diagnostico de Histiocitosis de Células de Langerhans.

Dos semanas después del procedimiento quirúrgico, el paciente fue evaluado nuevamente por los cirujanos orales, encontrando recuperación adecuada, sin síntomas de trismus o infección y sin dehiscencia del tejido. Debido a los resultados de patología, el paciente fue referido con un oncólogo pediátrico para una consulta de se- 
guimiento y tratamiento posterior. Después de la evaluación médica se encontraron lesiones menores en el hígado del paciente por medio de una tomografía computarizada del hígado. El paciente actualmente está bajo tratamiento de quimioterapia el cual durará un año.

El examen oral de la cita de seguimiento de 3 meses reveló que los tejidos blandos estaban sanos y con coloración normal. Áreas óseas afectadas se están recuperando adecuadamente. El paciente será evaluado por cirugía oral y maxilofacial cada seis meses y por odontopediatria cada tres meses (Fig. 3).

\section{DISCUSIÓN}

Si se considera que HCL inicialmente se presenta con una lesión oral, tener conocimiento sobre las manifestaciones orales puede reducir la morbilidad y mortalidad de esta enfermedad considerablemente. Aun cuando la enfermedad periodontal es rara en los pacientes pediátricos, el inicio temprano de periodontitis con destrucción de hueso el cual ocurre de manera bilateral, puede ser asociado con ciertas condiciones sistémicas tales como; Hipofosfatasia, Síndrome de Papillon-Lefevre, Neutropenia Cíclica, Displasia Fibrosa, Diabetes, Leucemia y Periodontitis prepuberal ${ }^{5}$. Las manifestaciones orales y periorales son comunes en pacientes con Histiocitosis de Células de Langerhans y basándose en esta evidencia niños con pérdida ósea severa no asociada con lesiones de trauma en dentición decidua deben ser examinados por la posibilidad de padecer esta enfermedad. El cráneo y las extremidades inferiores son las de mayor prevalencia extra oral cuando hay involucramiento óseo. Este caso enfatiza la necesidad de una perspectiva más extensa al momento de tratar condiciones inflamatorias. Las lesiones líticas necesitan ser evaluadas con la mentalidad que pueden ser causadas por condiciones
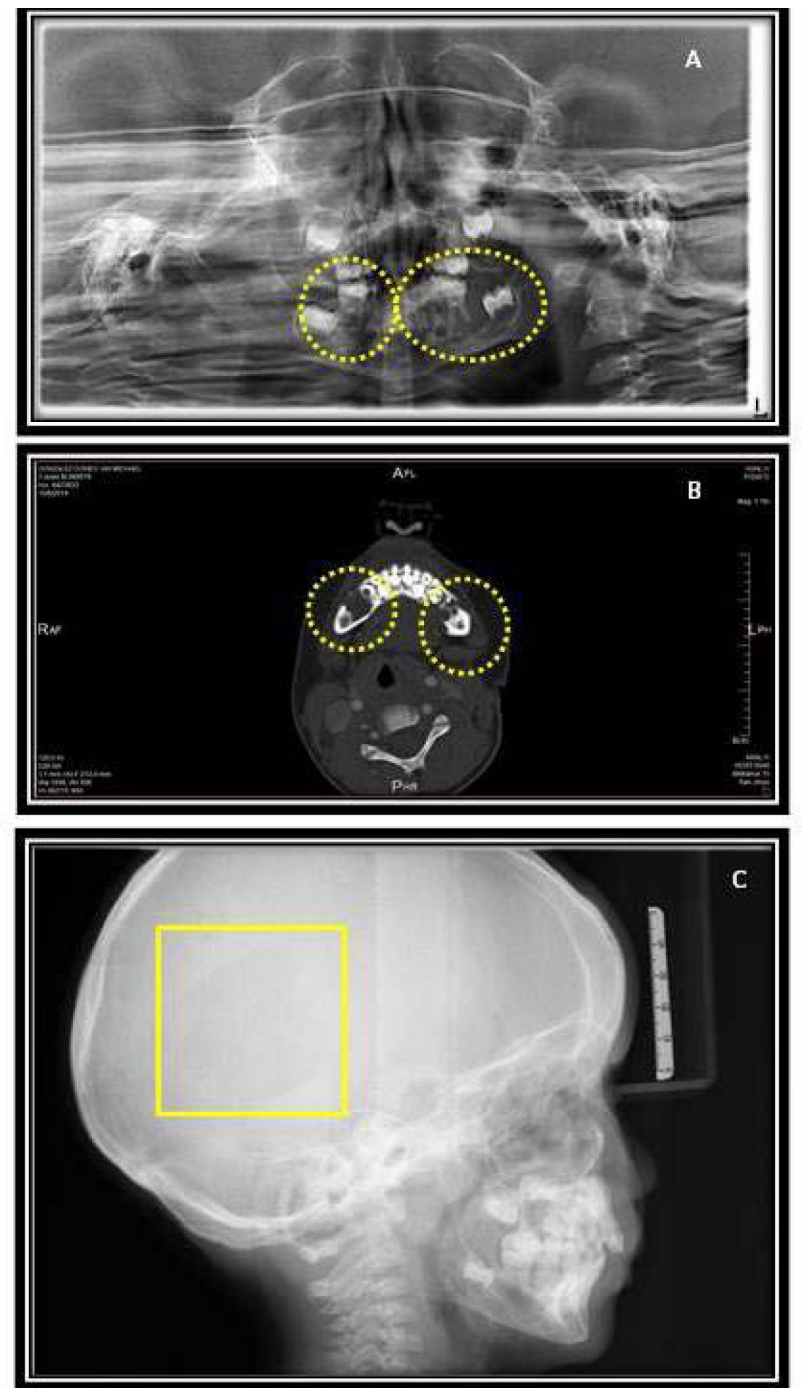

Figura 2.

inusuales. La similitud de lesiones inflamatorias de no ser identificadas correctamente puede conllevar una morbilidad y mortalidad excesiva.

\section{CONCLUSIÓN}

Este caso puntualiza la necesidad de que los pediatras y dentistas pediátricos/generales estén conscientes que HCL tiene similitudes con inflamaciones orales. Un acercamiento multidisciplinario es necesario para un diagnóstico y tratamiento adecuado además un seguimiento continuo para un manejo apropiado de la enfermedad. 


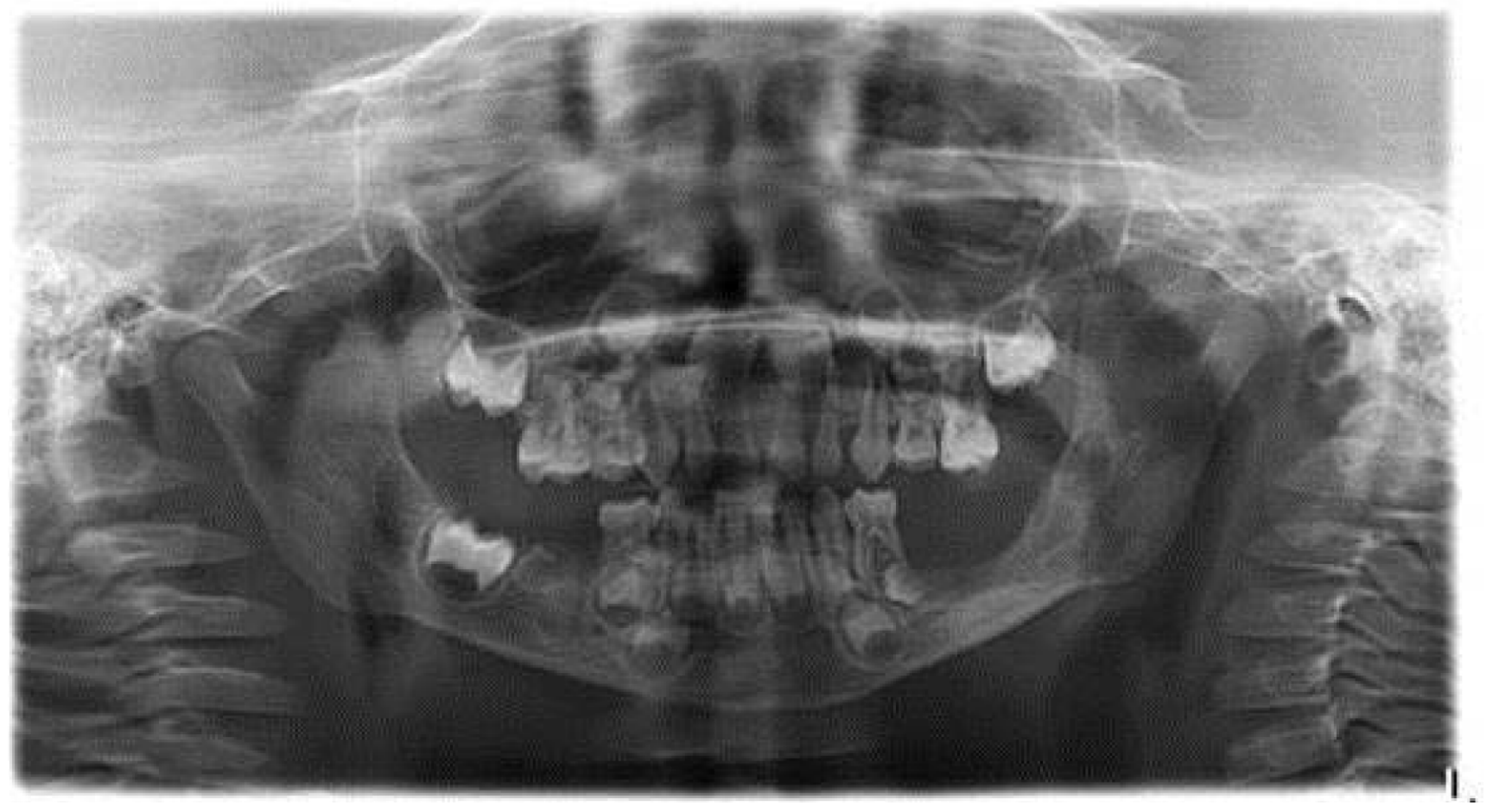

Figura 3.

\section{RECONOCIMIENTO}

Queremos agradecer los esfuerzos colectivos a mi mentora y Profesora Damaris Molina-Negrón de la Universidad de Puerto Rico, Escuela de Medicina Dental, Programa Posdoctoral en Odontopediatría, Profesora Lydia López del Valle de la Universidad de Puerto Rico, Escuela de Medicina Dental, Departamento de Investigación, sin ellas no hubiera sido posible, también a la Profesora Asociada Mirna Pacheco de la Escuela de Profesionales de la Salud, Asistente de Investigación Ricardo Ledesma y Director Asociado de Asuntos de Investigación Angeliz Encarnación Burgos por sus asistencia en edición.

\section{Conforme a los Estándares de Ética:}

Fondos: Este estudio no tiene fondos.

Conflictos de Interés: Todos los autores de este estudio declaran ningún conflicto de interés. Ningún tipo de fondos o manutención financiera fueron recibidos por ningún autor para este estudio.

Aprobación ética: Ningún tipo de animal fue utilizado para este estudio.

\section{(En caso de participación de humanos) Aprobación}

ética: Todos los procedimientos hechos en este estudio donde humanos participaron fueron hechos de acuerdo con los estándares de ética del comité institucional/nacional de investigación y con la declaración de Helsinki de 1964 y sus enmiendas posteriores o con otros estándares de ética comparables.

Consentimiento firmado por los padres/tutores legales del paciente, anexo se envía información suplementaria.

(En caso de participación de humanos) Consentimiento Informado: Consentimiento informado obtenido de todos los individuos participantes en este estudio. 


\section{Referencias bibliográficas}

1. Alshadwi, A., Nadershah, M., \& AlBazie, S. (2013). Langerhans cell histocytosis of the mandible in a pediatric patient. Journal of Dentistry for Children (Chicago, Ill.), 80(3), 145-9. Retrieved from http://www.ncbi.nlm.nih.gov/ pubmed/24351696

2 Divya, K. S. (2014). Oral manifestion of Langerhans cell histiocytosis mimicking inflammation. Indian Journal of Dental Research : Official Publication of Indian Society for Dental Research, 25(2), 228-30. http://doi.org/10.4103/09709290.135930

3 Eckardt, A., \& Schultze, A. (2003). Maxillofacial manifestations of Langerhans cell histiocytosis: a clinical and therapeutic analysis of 10 patients. Oral Oncology, 39(7), 687-94. Retrieved from http://www.ncbi.nlm.nih.gov/ pubmed/12907208

4 Madrigal-Martínez-Pereda, C., Guerrero-Rodríguez, V., Guisado-Moya, B., \& Meniz-García, C. (2009). Langerhans cell histiocytosis: literature review and descriptive analysis of oral manifestations. Medicina Oral, Patología Oral Y Cirugía Bucal, 14(5), E222-8. Retrieved from http://www.ncbi.nlm.nih.gov/pubmed/19218906

5 Minkov, M. (2011). Multisystem Langerhans cell histiocytosis in children: current treatment and future directions. Paediatric Drugs, 13(2), 75-86. http://doi.org/10.2165/11538540-000000000-00000

6 Shirley, J. C., \& Thornton, J. B. (2000). Oral manifestations of Langerhans' cell histiocytosis: review and report of case. ASDC Journal of Dentistry for Children, 67(4), 293-6. Retrieved from http://www.ncbi.nlm.nih.gov/pubmed/10997248 7 Slater, J. M., \& Swarm, O. J. (1980). Eosinophilic granuloma of bone. Medical and Pediatric Oncology, 8(2), $151-64$. Retrieved from http://www.ncbi.nlm.nih.gov/pubmed/6999317

8 Society, W. G. of the H. (1987). Histiocytosis syndromes in children. Lancet, 1(8526), 208-9. Retrieved from http://www. ncbi.nlm.nih.gov/pubmed/2880029

9 Yashoda-Devi, B., Rakesh, N., \& Agarwal, M. (2012). Langerhans cell histiocytosis with oral manifestations: a rare and unusual case report. Journal of Clinical and Experimental Dentistry, 4(4), e252-5. http://doi.org/10.4317/jced.50728

Recibido: 11/01/2017

Aceptado: 09/03/2017

Autor Correspondiente:

R. Da Fonseca, Programa Postdoctoral de Odontopediatria Universidad de Puerto Rico-Recinto de Ciencias Médicas, PO Box 365067, San Juan, PR 00936.: (310) 463-3294, (787) 758-2525 Ext. 1106, 2069, 1144, 1181

refonsecadds@gmail.com, renata.dafonseca@upr.edu 